\title{
Foreign direct investment with endogenous technology choice
}

\author{
H. Dawid \\ B. Zou
}




\title{
Foreign direct investment with endogenous technology choice *
}

\author{
Herbert Dawid ${ }^{\dagger} \quad$ Benteng Zou ${ }^{\ddagger}$
}

November 10, 2014

\begin{abstract}
In this paper, we analyze optimal foreign direct investment of a firm which operates in a duopolistic market. We characterize a technology spillover threshold and show that for an intensity of spillovers below this threshold, there is a unique locally asymptotic stable steady state with a positive capital stock in the developing country. Furthermore, we characterize how optimal foreign investment patterns and the investor's value function depend on the level of technology transferred and characterize the optimal level to be used for the foreign direct investment.
\end{abstract}

Keywords: Foreign direct investment, technology spillovers, optimal control JEL classification: F21, D92, C61

\footnotetext{
*We knowledge the support of COST Action IS1104: The EU in the new economic complex geography: models, tools and policy evaluation. And we appreciate the useful discussions with Luisito Bertinelli, Raouf Boucekkine, and Ioana Salagean.

${ }^{\dagger}$ Department of Business Administration and Economics and Institute of Mathematical Economics, Bielefeld University, E-mail: hdawid@wiwi.uni-bielefeld.de

${ }^{\ddagger}$ Corresponding Author: CREA, University of Luxembourg, 162a, avenue de la Faiencerie, L1511, Luxembourg. E-mail: benteng.zou@uni.lu
} 


\section{Introduction}

Based on UNCTAD statistic, worldwide foreign direct investment (FDI) had increased by a factor of more than 10 from 1983 to 2003. And this trend continues, from 2003 to 2013, the FDI inward and outward flows doubled again. While most FDI is still undertaken in industrialized countries, such as the US, Great Britain, France, Italy and the Netherlands, just to mention a few, more and more investment flows to the newly industrializing countries (NICs), especially Asian (mainly China and India) and Central and Eastern Europe, which have recently joined the EU. Indeed, the UNCTAD statistic presents that the emerging market takes more and more shares in the worldwide FDI, from less than 1/5 in 1983 to almost half in 2013 at the aggregate of inward and outward of FDI.

The motivation for firms to invest in NICs are primarily to get access to these markets and to benefit from in part drastically lower factor costs there. And cost reduction motivation becomes the main factor influencing the location decisions of firms. For example, Ireland provides a considerable tax incentive for foreign firms by offering a cor-

porate tax rate of 10 percent to all manufacturing firms producing in Ireland (see Görg and Greenaway, 2004). The reasons for governments to attract FDI seem to be clear. Investment raises employment and growth and may also generate positive spillover effects for local firms. The latter seems to be of particular importance for NICs, which hope to get access to modern technologies in this way. While there is empirical evidence that spillovers of FDI exist (see e.g. the survey by Lim, 2001). There are also econometric studies, nevertheless, fail to find unambiguously positive effects, see for example Aitken and Harrison (1999). One reason for this may be the lack of sufficiently good microeconomic data on the firm level (cf. Görg and Greenaway, 2004).

Nevertheless, great many empirical studies do find evidence for such spillover effects. Especially, Blomstrom et al. (2001) states "foreign investors make available (di- 
rectly or indirectly) appropriable to host country business. Appropriable technology should be viewed broadly as any tangible or intangible resource that can generate economic rent for host country firms, $\cdots$ by improving total factor productivity." Based on this kind of argument and via using new firm-level data for German and Italian manufacturing firms during the 1990s, Peri and Urban (2006) provide evidence of significant technological spillover effects "which is robust to various ways of measuring the total productivity of firms ...." More related literature can be seen in Dawid and Zou (2014).

In this paper, we follow some FDI literature, such as, Das (1987), Wang and Blomstrom (1992), Petit et al. (2000), Dawid et al. (2010), among others (for a survey of theoretical models, see Cheng (1984) or Saggi (2002)), and assume that the change in the host country's productivity is formulated as an increasing function of the presence of foreign capital stock. Here, multinational firm have to decide whether and, if so, how much to invest in a developing economy. Firm invests in physical capital, but investment in physical capital is associated with positive technology spillovers which raise the stock of knowledge of their competitors, thus, negatively affecting its own sales and reduces profits.

Differing from the above literature, we model the growth rate of technological spillover, rather than the technological change itself, depends on the accumulated capital stock and the technology gap. Thus, the main result is that we frame a technological spillover threshold. When the absorption rate of developing country is below this threshold, there is less possibility for technological spillover and hence it is beneficial to take advantage of developing country's low marginal cost of production. Thus, this kind of FDI leads to a long run steady state where there is positive capital stock in the developing country. Furthermore, this technological spillover threshold exposes information for high technique firms which kind of technology should take to the foreign country. 
The rest of the paper is organized as follows. In the next section we present the theoretical model. In section 3 we first analyze the long-run behavior of the investment policy of the firm, formulate the technological spillover threshold and provide information on which level of technology should take for FDI. Then, via numerical method, we present the trajectory dynamics under different cases. Section 4 concludes.

\section{The model}

We consider a dynamic two-country model where country $\mathrm{H}$ ('home country') is a developed industrialized country whereas country $\mathrm{F}$ ('foreign country') is a newly industrializing country. We denote by $Q_{i}(t)$ the output of firm $i$ at time $t, i=H, F$.

Firms produce using labor as the only variable production input. Production capacities of a firm in a country are determined by its capital stock there. Output per input unit in the two countries is given by $A_{H}(t)$ and $A_{F}(t)$ with $A_{H}(t)>A_{F}(t)$. If the firm from country $\mathrm{H}$ produces in country $F$, productivity reads $A_{H F}(t)$ where initially $A_{F}(0)<A_{H F}(0)<A_{H}(0)$. Since our focus is on the effects of technological spill-overs generated by FDI on the evolution of the technology gap between the two countries, we abstract from technological change in the developed country. The technology, $A_{H F}$, which firm $H$ takes to invest in country $\mathrm{F}$, may change over time depending on the situation in country $F$ given $A_{F}(t)$ may change over time due to spill-over effects. In both countries labor is supplied at wage rates $w_{H}$ and $w_{F}$, where $w_{H}>>w_{F}$.

We assume that firms in country $H$ can reduce their unit production costs if they produce in the foreign country, i.e.,

$$
\frac{w_{H}}{A_{H}}>\frac{w_{F}}{A_{H F}} .
$$

In order to produce abroad, firm $\mathrm{H}$ has to invest to build up production capacities in country F. We denote by $I(t) \in \mathcal{R}$ foreign investment of firm $\mathrm{H}$ and by $K_{F}(t)$ the 
capital stock of firm $\mathrm{H}$ in country $F$ at time $t$. It should be noted that we also allow for negative investment, and due to the spillover-effects described below disinvestment might in principle be optimal for firm $\mathrm{H}$. The capital accumulation equation is given by

$$
\dot{K}_{F}(t)=I(t)-\delta K_{F}(t)
$$

where $\delta$ is the depreciation rate of capital and $I \in \mathbb{R}$ which reads if $I>0$ there is positive investment, while $I<0$, disinvestment is possible.

Foreign direct investments of firm $H$ in country $\mathrm{F}$ generate technological spill-overs. Following the classical literature Nelson and Phelps (1966) and more recent empirical contribution, such as Peri and Urban (2006), we posit that the change in technology level in the foreign country is determined by the absorption rate $\lambda$, the accumulated past investment $K_{F}$ and the technological gap, $A_{H F}(t)-A_{F}(t)$. Nonetheless, the empirical contribution of Peri and Urban (2006) and our recent theoretical studies, Dawid and Zou (2014), notice that the absorption depends also on the efforts and technological level of country F. As Hymer (1960) and Blomstrom et al. (2001) already mention that foreign direct investment does not only transfer physical capital, but also transfers management and new technology via spillover effects. We call all, with exception of physical capital, as technology and measure the effort of foreign country by its technological level. Thus, in the following we combine both the absorption rate and the technology $A_{F}$ of firm $F$ together and denote $\lambda A_{F}(t)$ as absorption ability. Hence, the law of motion of technology of firm $F$ is governed by

$$
\dot{A}_{F}(t)=G\left(\lambda, A_{F}(t), K_{F}(t), A_{H F}(t)-A_{F}(t)\right)=\lambda A_{F}(t) K_{F}(t) \cdot\left(A_{H F}-A_{F}(t)\right)
$$

with initial condition $A_{F}(0) \in\left(0, A_{H}\right)$ given. A different interpretation of (3) can be given by rewriting it as

$$
\frac{\dot{A}_{F}(t)}{A_{F}}=\lambda K_{F}(t) \cdot\left(A_{H F}-A_{F}(t)\right) .
$$


Thus, different from Dawid et al. (2010), we assume the technological growth rate of country F due to FDI is determined by the accumulated capital stock and the technology gap.

Except the investment of firm $H$, both firms at each point of time also choose their output quantities based on Cournot competition, given that the output choices do not have any intertemporal implications. And the marginal costs are $c_{H}=\frac{W_{H}}{A_{H}}, c_{F}(t)=$ $\frac{W_{F}}{A_{F}(t)}$, where for simplicity, we assume that foreign investment will not increase the wage rate in the country $F$.

In the following, we take linear demand function and the inverse demand function is given by

$$
P(t)=\bar{P}-\left(Q_{H}+Q_{F}\right)
$$

where $\bar{P}$ is a positive constant reservation price. Then, the existence and uniqueness of Cournot equilibrium for our duopolistic market with heterogenous marginal production cost are demonstrated in detail by Dawid et al (2010). Furthermore, the equilibrium outputs and price in the duopolistic market are given as follows:

$$
\begin{aligned}
Q^{*} & =Q_{H}^{*}+Q_{F}^{*}, \quad Q_{H}^{*}\left(A_{F}\right)=\frac{\bar{P}-2 \frac{w_{H}}{A_{H}}+\frac{w_{F}}{A_{F}}}{3}, \quad Q_{F}^{*}\left(A_{F}\right)=\frac{\bar{P}-2 \frac{w_{F}}{A_{F}}+\frac{w_{H}}{A_{H}}}{3}, \\
P^{*} & =\frac{\bar{P}+\frac{w_{H}}{A_{H}}+\frac{w_{F}}{A_{F}}}{3} .
\end{aligned}
$$

Therefore, firm H's equilibrium profit is

$$
\begin{aligned}
& \Pi_{H}^{*}\left(K_{F}, A_{F}\right)=Q_{H}^{*}\left(A_{F}\right)\left(P^{*}\left(A_{F}\right)-\frac{w_{H}}{A_{H}}\right)+K_{F} A_{H F}\left(\frac{w_{H}}{A_{H}}-\frac{w_{F}}{A_{H F}}\right) \\
& =\left(Q_{H}^{*}\left(A_{F}\right)\right)^{2}+K_{F}\left(\frac{w_{H}}{A_{H}} A_{H F}-w_{F}\right) .
\end{aligned}
$$

In the following, we impose condition such that even the wage rate, $w_{F}$, in country $F$ is sufficiently low, there is still positive output produced by firm $H$ - marginal production cost of firm $H$ is not too high. 
Assumption $1 \bar{P}>2 \frac{w_{h}}{A_{H}}$.

A first observation is the following:

Lemma 1 Profit function $\Pi_{H}^{*}$ is continuously differentiable with respect to $A_{F}$ and $K_{F}$. Moreover,

$$
\frac{\partial \Pi_{H}^{*}}{\partial A_{F}}=-\frac{2 Q_{H}^{*}\left(A_{F}\right) w_{F}}{3 A_{F}^{2}}<0
$$

and

$$
\frac{\partial \Pi_{H}^{*}}{\partial K_{F}}=A_{H F}\left(\frac{w_{H}}{A_{H}}-\frac{w_{F}}{A_{H F}}\right)>0, \text { iff } \frac{w_{H}}{A_{H}}-\frac{w_{F}}{A_{H F}}>0
$$

Indeed, this Lemma demonstrates the conflict, from firm $H^{\prime}$ s point of view, of foreign direct investment which we introduced in the introduction: on the one hand, FDI reduces firm $H^{\prime}$ s cost and hence increases its profit; but on the other hand, FDI with technological spillover induces more competition and thus deduces profit of firm $H$.

In the following section we analyze the dynamic optimization problem of Firm H. We consider how the outcomes change when the technological spillover depends on $A_{F}$, except the technological gap $A_{H F}-A_{F}$.

\section{The dynamic optimization problem of Firm $\mathbf{H}$}

After having determined the optimal level of production, firm $\mathrm{H}$ faces the intertemporal problem of choosing optimal investment strategy, $I(t) \in \mathbb{R}$, to maximize its profit:

$$
\max _{I} J_{H}=\max _{I} \int_{0}^{\infty} e^{-r t}\left[\Pi_{H}^{*}\left(K_{F}, A_{F}\right)-\left(\beta I+\gamma I^{2}\right)\right] d t
$$

subject to accumulation of capital (2), technological spillover (3) with $K_{F}(0)$ and $A_{F}(0)$ given, and the state constraint

$$
K_{F}(t) \geq 0, \quad \forall t \geq 0
$$


where $r>0$ is the time preference parameter. $\beta I+\gamma I^{2}$ are gross investment costs, while $I$ are net investment costs, with unit adjustment $\gamma$ a positive constant and purchasing $\operatorname{cost} \beta>0$ playing the role of Tobin's $q$. The difference between gross and net investment cost is due to purchasing and adjustment costs of investment.

\subsection{The dynamics}

In what follows, we shall characterize the inter-temporally optimal investment for firm H. Applying Pontryagin's maximum principle and standard Lagrangian method, a canonical system of ordinary differential equations can be derived that has to be satisfied by the optimal trajectories. However, since the optimized Hamiltonian of the dynamic optimization problem of firm $\mathrm{H}$ is not concave with respect to the two state variables, $K_{F}$ and $A_{F}$, the Maximum principle provides only necessary but not sufficient optimality conditions (see e.g. Dockner at al. (2000)). Nevertheless, Dawid et al. (2010) demonstrate that the choice presented in the following proposition are optimal.

Proposition 1 For any state trajectory $\left(K_{F}(t), A_{F}(t)\right)$ that corresponds to an optimal strategy of firm $H$, there exist piecewise absolutely continuous co-states $\mu_{K}(t), \mu_{A}(t)$, and a multiplier $\eta(t) \geq 0$, such that, the optimal investment is

$$
I(t)=\frac{\mu_{K}(t)-\beta}{2 \gamma}
$$

and the costate equations are

$$
\begin{aligned}
& \dot{\mu_{K}}=(\delta+r) \mu_{K}-\mu_{A} \lambda A_{F}\left(A_{H F}-A_{F}\right)-A_{H F}\left(\frac{w_{H}}{A_{H}}-\frac{w_{F}}{A_{H F}}\right)-\eta, \\
& \dot{\mu_{A}}=r \mu_{A}-\mu_{A} \lambda K_{F}\left(A_{H F}-2 A_{F}\right)-\frac{\partial \Pi_{H}^{*}\left(K_{F}, A_{F}\right)}{\partial A_{F}} .
\end{aligned}
$$

Furthermore, the multiplier checks

$$
\eta K=0, \eta \geq 0, \quad \forall t \geq 0
$$


and the transversality conditions $\lim _{t \rightarrow \infty} e^{-r t} \mu_{K} K_{F}=0, \lim _{t \rightarrow \infty} e^{-r t} \mu_{A} A_{F}=0$ are satisfied. In addition, at any time $\tau$ where the trajectory hits the boundary $K=0$, the co-state $\mu_{K}$ might have a jump with $\lim _{t \rightarrow \tau-} \mu_{K}(t) \geq \lim _{t \rightarrow \tau+} \mu_{K}(t)$.

In the following subsection, we characterize the potential steady states of the system under optimal investment and analyze how the initial technology gap, $\left(A_{H F}-A_{F}\right)$, and firm F's technology, $A_{F}$, determine which steady state is reached.

Rest points of the differential equations (2), (3), (9) and (10) give steady states for our model. It is easy to see that there are two different steady states: (I) Catching-up steady state with $K_{F} \neq 0$ and (II) left-behind steady state with $K_{F}=0$.

\subsection{Steady states}

Let us first study the steady state with $K_{F} \neq 0$. Setting $\dot{A}_{F}=0, \dot{K}_{F}=0, \dot{\mu}_{K}=0, \dot{\mu}_{A}=0$, we obtain the other variables of this steady state as

$$
\left\{\begin{array}{l}
\widehat{\eta}=0 \\
\widehat{A_{F}}=A_{H F}, \\
\widehat{\mu_{K}}=\frac{A_{H F}}{\delta+r}\left(\frac{w_{H}}{A_{H}}-\frac{w_{F}}{A_{H F}}\right) \\
\widehat{I}=\delta \widehat{K_{F}}=\frac{\widehat{\mu_{K}}-\beta}{2 \gamma}, \\
\widehat{\mu_{A}}=-\frac{1}{r+\lambda \widehat{K_{F}} A_{H F} / 2} \frac{\partial \prod_{H}^{*}\left(\widehat{K_{F}}, \widehat{A_{F}}\right)}{\partial A_{F}} .
\end{array}\right.
$$

To guarantee nonnegative investment and capital stock at the steady state, if and only if $\widehat{\mu_{K}}>\beta$, which is equivalent to the following condition:

\section{Assumption 2}

$$
\beta<\frac{A_{H F}}{r+\delta}\left(\frac{w_{H}}{A_{H}}-\frac{w_{F}}{A_{H F}}\right) .
$$


The economic meaning of this assumption is straightforward by recalling that the right hand side reads the gain from unit capital invested in country F. Thus, with positive long-run investment and capital stock in the foreign country, the gain should be larger than the purchasing price.

As concerns existence and stability of catching-up steady state, it turns out that the absorption rate plays a crucial role in that respect. Define

$$
\bar{\lambda}=-\frac{4 r}{A_{H F}^{2}}\left(A_{H F}\left(\frac{w_{H}}{A_{H}}-\frac{w_{F}}{A_{H F}}\right)-\beta(r+\delta)\right) / \frac{\partial \Pi_{H}^{*}\left(0, A_{H F} / 2\right)}{\partial A_{F}}
$$

as the threshold for the spillover intensity. It is easy to check that this threshold, $\bar{\lambda}$, increases with the difference of marginal costs, $\left(\frac{w_{H}}{A_{H}}-\frac{w_{F}}{A_{H F}}\right)$, and the given FDI technology, $A_{H F}$.

The next proposition shows that as long as the intensity is below this level, catchingup steady state is the unique long-run steady state.

Proposition 2 Given Assumption 1, 2 and FDI technology $A_{H F} \in\left(A_{F}(0), A_{H}\right) \subset\left(0, A_{H}\right)$, there exists a $\bar{\lambda}>0$, which is given by (12), such that, for every $\lambda<\bar{\lambda}$, steady state (11) is the unique steady state. Furthermore, this steady state is locally asymptotic stable in its state space.

Proof: See appendix.

The Proposition 2 states that there exists a situation such that it can be optimal for the home country firm to build up a capital stock in the developing country, $\widehat{K_{F}}>0$, in the long-run. However, besides this outcome, it is also possible that the firm does not invest in the developing country in the long-run, so that $\widehat{K_{F}}=0$ holds. Whether there exist two steady states or only one catching-up steady state depends on the parameter $\lambda$, which determines how fast the developing country absorbs the new technology.

So, for $\lambda>\bar{\lambda}$ both steady states may be feasible, while for $\lambda<\bar{\lambda}$ only steady state with $\widehat{K_{F}}>0$ exists. From an economic point of view, the latter case means that the firm 
will always maintain a capital stock in the developing country and produce there if the catching-up speed of the developing country is small. Recalling that investment in the developing country increases the level of technology of the firms there and, thus, the competitiveness of these firms, this outcome is plausible. If this process is slow, the negative effect of investing in the foreign country, i.e. the spillovers, only takes place gradually. Therefore, for small values of $\lambda$ it is always optimal to invest in the developing country in the long-run. It should also be noted that the value of $\lambda$ does not affect the steady state values of investment and capital in the developing country in steady state.

Before closing this section, we notice that the threshold condition (12) is given in relative term of marginal production cost and FDI technology $A_{H F}$. Thus, from a different point of view, the threshold condition imposes very important information for FDI technology $A_{H F}$. To make this point clear, we first rewrite condition (12) as the following

$$
\left.\bar{\lambda} A_{F}\left(A_{H F}-A_{F}\right)\right|_{A_{F}=A_{H F} / 2}=-r\left(A_{H F}\left(\frac{w_{H}}{A_{H}}-\frac{w_{F}}{A_{H F}}\right)-\beta(r+\delta)\right) / \frac{\partial \Pi_{H}^{*}\left(0, A_{H F} / 2\right)}{\partial A_{F}},
$$

where the left hand side states firm F's benchmark absorption ability, $\bar{\lambda} A_{F}$, considering the technology gap $\left(A_{H F}-A_{F}\right)$ and evaluated at $A_{F}=A_{H F} / 2$, which is the optimal level of Firm F's technological change, i.e., maximum of the right hand side of equation (3). The right hand side of (13) is the unit gain-loss-ratio, where the gain comes from cost reduction from FDI, due to Assumption 2, and the loss comes from the technological spillover to firm F; and the ratio is discounted by time preference $r$.

Thus, condition $\lambda<\bar{\lambda}$ reads that, from the point of view of firm $\mathrm{H}$, the optimal spillover, taking into account the technological gap and foreign firm's absorption ability, should not be larger than firm H's gain-loss-ratio of taking this FDI. Put this condi- 
tion differently, $\lambda<\bar{\lambda}$ condition is equivalent to

$$
\lambda<-\frac{4 r}{A_{H F}^{2}}\left(A_{H F}\left(\frac{w_{H}}{A_{H}}-\frac{w_{F}}{A_{H F}}\right)-\beta(r+\delta)\right) / \frac{\partial \Pi_{H}^{*}\left(0, A_{H F} / 2\right)}{\partial A_{F}},
$$

Changing the notation, it yields

$$
A_{H F}<-\frac{4 r}{\lambda A_{H F}}\left(A_{H F}\left(\frac{w_{H}}{A_{H}}-\frac{w_{F}}{A_{H F}}\right)-\beta(r+\delta)\right) / \frac{\partial \Pi_{H}^{*}\left(0, A_{H F} / 2\right)}{\partial A_{F}},
$$

which implicitly states the optimal FDI technology, that is, the FDI technology should be no more than the unit gain-loss-ratio by taking into account the discounting rate and firm F's absorption ability, $\lambda A_{F}$, and all evaluated at the maximum growth rate of spillover, here, $A_{F}=A_{H F} / 2$.

More precisely, given firm $\mathrm{F}^{\prime} \mathrm{s}$ absorption rate $\lambda$, rewriting the above inequality in term of $A_{H F}$ yields that $A_{H F}$ has to satisfy the following second order polynomial inequality condition:

$$
9 r \frac{w_{H}}{A_{H}} A_{H F}^{2}-\left[9 r\left(w_{F}+\beta(r+\delta)\right)+2 \lambda w_{F}\left(\bar{P}-2 \frac{w_{H}}{A_{H}}\right)\right] A_{H F}-4 \lambda w_{F}^{2}>0,
$$

which always has two roots with one negative and one positive. Denote the positive root as $A_{H F}^{m}$. Thus, the optimal choice of FDI technology, from the above inequality, must satisfies: $A_{H F}>A_{H F}^{m}$.

We conclude this finding in the following:

Proposition 3 Suppose Assumption 1 and 2 hold, let $\lambda>0$ be given constant firm F's absorption rate, then the sufficient condition for keeping positive FDI is that FDI technology checks

$$
\max \left\{A_{F}(0), A_{H F}^{m}\right\}<A_{H F} \leq A_{H},
$$

where $A_{H F}^{m}$ is the positive root of (14).

Though this result does not offer optimal FDI technology, it indeed implies the lower bound of FDI technology. The left hand side inequality reads that too low FDI 
technology (such as, $A_{H F}<A_{H F}^{m}$ ) is not advance enough to compensate the cost induced by FDI technology spillover. The last inequality is a surprising results, which states that the FDI technology could be the most advanced one of firm $\mathrm{H}$. The reason for this is twofold: on the one hand, the catching-up process of firm F, via equation (3), reaches its maximum level at $A_{F}=\frac{A_{H F}}{2}$ and decreases its catching-up speed after that ${ }^{1}$. In other words, the closer the technology of firm $\mathrm{F}$ to the level of $A_{H F}$, the harder is it to catch up ${ }^{2}$. Keeping this in mind, then on the other hand, the gain from higher FDI technology is much higher than with lower one, which is given by $\left(A_{H F}\left(\frac{w_{H}}{A_{H}}-\frac{w_{F}}{A_{H F}}\right)-\beta(r+\delta)\right) / \frac{\partial \Pi_{H}^{*}\left(0, A_{H F} / 2\right)}{\partial A_{F}}$.

Therefore, combining these two sides together, for given absorption rate of the foreign country, the above proposition indeed provides information of FDI technology, which is new in literature.

We close this subsection by noticing that the second steady state implies that the home country firm $\mathrm{H}$ does not produce in the developing country in the long-run, i.e. $\overline{K_{F}}=0$ holds. This implies that investment in steady state equals zero, $\bar{I}=0$, and $\overline{\mu_{K}}=\beta$. Similar arguments as Dawid et al. (2010), we can finish the rest study of this steady state, which we do not repeat here.

\subsection{Dynamics and the Effect of $A_{H F}$ on the Value Function}

Having discussed sufficient conditions under which the only steady state under optimal behavior of firm $H$ induces full catch-up of the firm $F$ to the technology level transferred by $H$, we now return to the question which level of technology should be transferred by firm $H$. To formulate this question more precisely, we will explore now how the choice of $A_{H F}$ affects the value function of firm $H$ for a given initial techno-

\footnotetext{
${ }^{1}$ That does not mean the catching-up stop, actually, $\dot{A_{F}} \geq 0$, for all $t \geq 0$.

${ }^{2}$ That also confirms a similar finding of Dawid and Zou (2014) with endogenous effort of absorption under a differential game setting.
} 
logical level $A_{F}(0)$ of firm $F$.

In order to address this question we need to calculate the value function of firm $H$ for different values of $A_{H F}$ in order to compare them. The dynamic optimization problem of the firm does not have any special structure that would allow to derive a closed form analytical expression for the value function. Therefore, we rely on numerical methods to calculate the value function of the problem. In particular, we employ a collocation method based on a Chebychew polynomial approximation of the value function (see Dawid and Zou (2014) or Vedenov and Miranda (2001) for details about this method.). The standard parameter setting for the following analysis is given in Table 1.

$$
\begin{array}{crc}
A_{H}=4 & A_{F}(0)=1.7 & r=0.03 \\
\beta=0 & \gamma=500 & \delta=0.06 \\
\bar{P}=5 & w_{H}=4 & w_{F}=1
\end{array}
$$

Table 1: Standard parameter setting

It should be noted that under this parameter setting the unit costs of production in the own country (without any spillovers) are lower for firm $F$ than for firm $H$ (i.e. $\left.w_{F} / A_{F}(0)<w_{H} / A_{H}\right)$. This implies that firm $H$ can profit from transferring production to country $F$ with a level of technology that is already used in that country (i.e. $A_{H F}=$ $\left.A_{F}(0)\right)$. In such a case firm $H$ can reduce own production costs without inducing any increase of the productivity of its competitor in country $F$. As we will show below that this does however not necessarily imply that foreign investment is profitable for firm $H$ for any value of $A_{H F} \in\left[A_{F}(0), A_{H}\right]$.

In Figure 1 we show the value function $V\left(0, A_{F}(0)\right)$ of firm $H$ (i.e. the maximal discounted profit stream for firm $H$ starting from no initial capital in country $F$ and an 


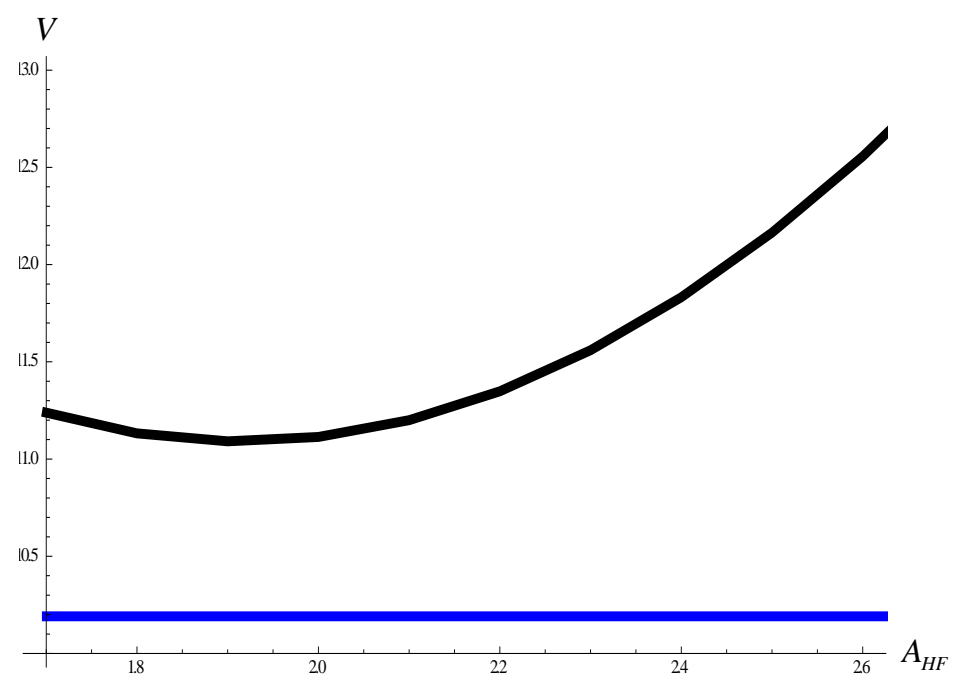

Figure 1: The value function $V(0,1.7)$ of firm $H$ for $A_{H F} \in[1.7,2.6]$ under the standard parameter setting.

initial technology level $A_{F}(0)$ for firm $F$ ) if the productivity of transferred technology varies in an interval above $A_{F}(0)$. The blue horizontal line in the figure indicates the discounted profit for firm $H$ if it does not engage in any FDI. It can be clearly seen that for the standard parameter setting it is profitable for the firm to move part of its production to country $F$ regardless of the choice of $A_{H F}$. Furthermore, the figure indicates that the relationship the level of the transferred technology and the value function of firm $H$ is not monotonous. For large values of $A_{H F}$ there is a positive relationship, implying that transferring the best available technology to firm $H$ is optimal if the productivity in country $F$ induced by such a transfer is close to $A_{H}$. However, in the lower part of the considered range for $A_{H F}$ the relationship is negative, which implies that, if for some reason firm $H$ cannot generate a productivity in country $F$ that is substantially larger than the productivity of the local firm (in our parameter setting the threshold is approximately $A_{H F}=2.0$ ), then it is optimal for firm $H$ to use the same technology in country $F$ that is already used by firm $F$, thereby avoiding any spillovers 
to the local firm.

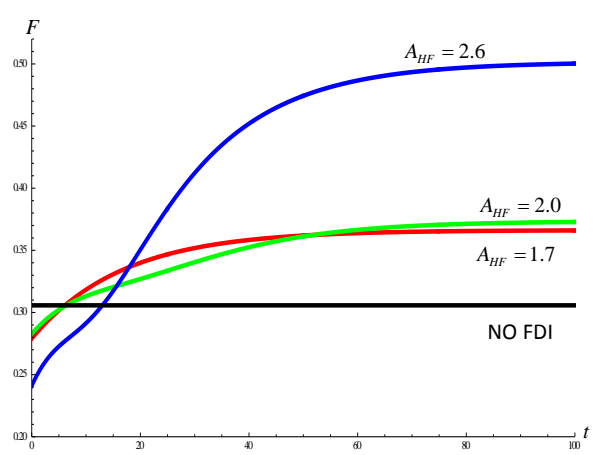

(a)

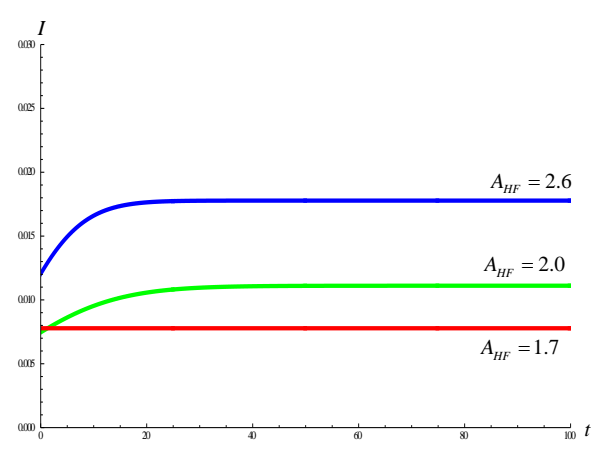

(b)

Figure 2: Dynamics of instantaneous profits (= instantaneous utilities) (a) and investments (b) of firm $H$ under $A_{H F}=1.7$ (red line), $A_{H F}=2.0$ (green line) and $A_{H F}=2.6$ (blue line). The back line in panel (a) indicates instantaneous profits of firm $H$ if it produces only in country $H$.

To gain a better understanding of the reasons for the non-monotonicity of the value function of firm $H$ we consider in Figure 2 the dynamics of instantaneous profits, that is, instantaneous utilities, and optimal investments of firm $H$ for three different values of $A_{H F}$. In panel (a) we also depict as a reference point the (constant) profit of firm $H$ if it does not engage in any foreign investment (black line). The blue trajectories correspond to the case where firm $H$ transfers an advanced technology to country $F$ such that the productivity of firm $H$ in country $F$ is much larger than the productivity of the local firm $F$. It can be clearly seen in panel (a) that initially instantaneous payoffs of firm $H$ are lower compared to a scenario where it would not engage in FDI. The reason clearly is that the firm has to cover substantial investment costs, whereas initially the capital stock in country $F$ is so small that no large cost reductions can be achieved. In the long run, however the cost savings for firm $H$ dominate the investment costs and the negative effect on prices induced by the catching-up of firm $F$. The long run 
profits of firm $H$ under the transfer of this high technology are the largest among the four considered scenarios, which explains why the value function for firm $H$ is largest for high values of $A_{H F}$.

A similar picture emerges if we consider the trajectories for $A_{H F}=2.0$ with the difference that investment intensity is much smaller that for $A_{H F}=2.6$. Initially this saves costs for firm $H$, and therefore initial profits are larger than under $A_{H F}=2.6$, but in the long run, the cost saving effect is smaller inducing much smaller long run profits. If the level of technology transferred is further reduced to $A_{H F}=1.7$, which means that the same technology is used by firm $H$ than by firm $F$, the qualitative implications of a decrease in $A_{H F}$ change. First, for a very short initial period the investment under $A_{H F}=1.7$ is actually larger than under $A_{H F}=2.0$. The reason for this observation is that for $A_{H F}=1.7$ no spillovers are generated, which means that firm $H$ faces no negative externalities of its investment. This increases the incentives to invest. Also in the long run the profits under $A_{H F}=1.7$ are smaller than under $A_{H F}=2.0$. Like discussed above this is due to the fact that the larger cost-savings gained in the longrun under $A_{H F}=2.0$ outweigh the (negative) long-run price effects induced by the spillovers to firm $F$. However, in an medium-run time window (approx. $t=5$ to $t=50)$ the profits of firm $H$ under $A_{H F}=1.7$ are substantially larger than under $A_{H F}=2.0$. In this time window the relatively small capital stock in country $F$ prevents large differences in the cost savings for firm $H$ under the two scenarios, and therefore the price effect induced by the spillovers generated under $A_{H F}=2.0$ (and absent under $\left.A_{H F}=1.7\right)$ dominates. Figure 1 shows that the profit difference in this intermediate time window is sufficiently large to make the discounted profit stream of firm $H$ larger under $A_{H F}=1.7$.

For our standard parameter setting the FDI is profitable for firm $H$ regardless of the level of technology that is transferred, but in scenarios with larger investment costs choosing the right value of $A_{H F}$ can be essential to make FDI profitable. To illustrate 


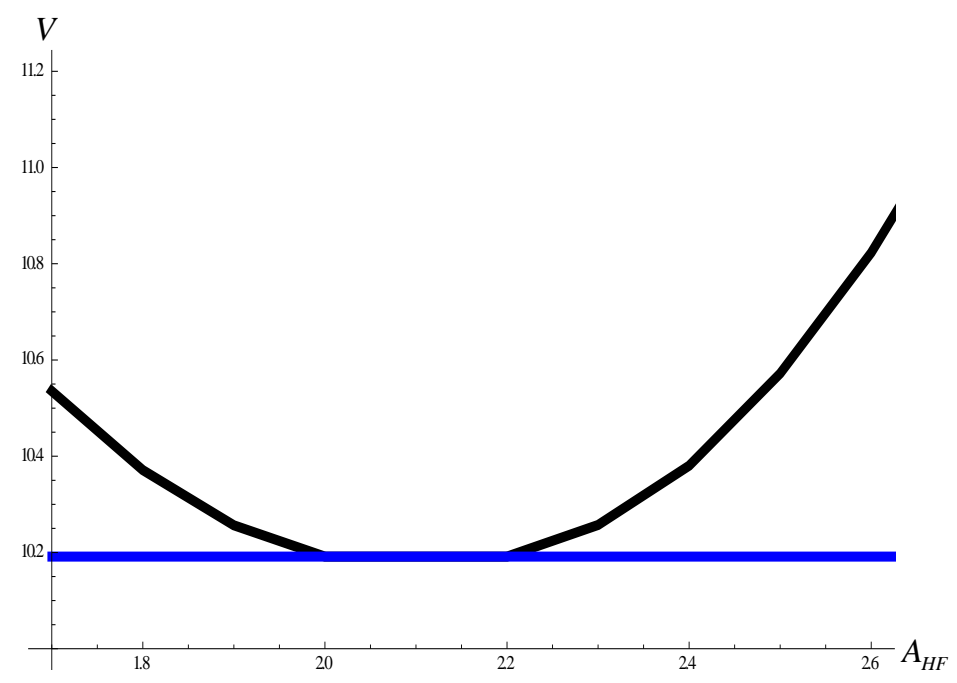

Figure 3: The value function $V(0,1.7)$ of firm $H$ for $A_{H F} \in[1.7,2.6]$ and $\beta=3.5$.

this we show in Figure 3 the value function of firm $H$ for $A_{F}(0)=1.7, K_{F}(0)=0$ and a positive price of foreign capital of $\beta=3.5$. As expected, increasing the investment cost parameter $\beta$ shifts the value function downwards. The $\mathrm{U}$-shape of the function stays unchanged, and, as becomes clear from Figure 3, there is a range of value of $A_{H F}$ for which investment in country $F$ is not profitable for firm $H$. For these values the sum of the investment costs and the externalities through spillovers outweigh the cost savings that can be optimally gained and it is therefore optimal for firm $H$ to refrain from any investments. Interestingly, there is however an interval of $A_{H F}$ value both above and below this range such that FDI is profitable.

\section{Conclusion}

In this paper, we have presented a dynamic model of the firm from a developed country which operates in an duopolistic market. The firm has an incentive to invest and 
produce in a developing country to reduce production cost, but due to spillover, this investment raises the technology level of its competitors in the developing economy.

Following literature on absorptive capacity we assume that the intensity of the spillovers does not only depend on the size of the foreign capital stock of the hightech firm and the size of the technological gap, but also on the accumulated efforts to absorb the spillovers. Here, we measure these kind of efforts by the technology level in low-tech country.

We could demonstrate that there exists a unique steady state with a positive capital stock in the developing economy if the speed of technology transfer is below a certain threshold, which is determined by the optimal growth rate of spillover of technology. This makes sense from an economic point of view. If the catching-up process is relatively slow, the firm can be assured that the competitiveness of the firms in the developing country rises only slowly, so that it is optimal to build up a capital stock in the developing country in the long-run.

As a by-product, the threshold of absorption rate implicitly imposes conditions under which the high technology firm $\mathrm{H}$ should engage in FDI.

Based on numerical calculations we have then shown that the value function of firm $H$ depends in a non-monotonic way on the level of transferred technology $A_{H F}$. In particular, we have demonstrated that using the technology that is already established in the foreign country is more profitable for firm $H$ than transferring a better technology as long as the gap between the established and the transferred technology is not too large. 


\section{A Appendix}

\section{A.1 Proof of Proposition 1}

The Hamiltonian for the investment problem of firm $\mathrm{H}$ is given by

$$
\begin{aligned}
\mathcal{H}\left(K_{F}, A_{F}, \mu_{K}, \mu_{A}, \nu\right) & =\Pi_{H}^{*}\left(K_{F}, A_{F}\right)-\beta I-\gamma I^{2}+\mu_{K}\left(I-\delta K_{F}\right) \\
& +\mu_{A} \lambda A_{F} K\left(A_{H F}-A_{F}\right)
\end{aligned}
$$

and, taking into account the state-constraint, we obtain the Lagrangian

$$
\begin{aligned}
\mathcal{L}\left(K_{F}, A_{F}, \mu_{K}, \mu_{A}, \nu\right)=\Pi_{H}^{*}\left(K_{F}, A_{F}\right)-\beta I-\gamma I^{2}+\mu_{K}\left(I-\delta K_{F}\right) \\
\quad+\mu_{A} \lambda A_{F} K\left(A_{H F}-A_{F}\right)+\eta K .
\end{aligned}
$$

By Pontryagin's maximum principle, for every optimal investment path there must exist piecewise absolutely continuous co-states $\mu_{i}(t)$ and a piecewise continuous multiplier $\eta(t) \geq 0$, such that, investment at each time $t$ maximizes $\mathcal{L}$, the co-states satisfy the equations

$$
\begin{aligned}
& \dot{\mu}_{1}=\rho \mu_{1}-\frac{\partial \mathcal{L}}{\partial K_{F}}, \\
& \dot{\mu}_{2}=\rho \mu_{2}-\frac{\partial \mathcal{L}}{\partial A_{F}},
\end{aligned}
$$

for the multiplier $\eta K=0, \forall t \geq 0$, and the transversality conditions are satisfied. Furthermore, for each time $\tau_{i}$ of discontinuity of $\mu_{K}$, there exists an $\eta\left(\tau_{i}\right) \geq 0$ with

$$
\lim _{t \rightarrow \tau_{i}+} \mu_{K}(t)=\lim _{t \rightarrow \tau_{i}-} \mu_{K}(t)+\nu\left(\tau_{i}\right)
$$

Because in our problem no movement of the state on the $K=0$ line is possible, the problem is time autonomous and has an infinite time horizon, it is obvious that an optimal trajectory can never leave the boundary once it has hit it. Therefore, the only possible discontinuity of $\mu_{K}$ may occur at the time when the optimal trajectory hits the $K=0$ line. Direct calculation yields the Proposition. 


\section{A.2 Proof of Proposition 2}

The proof is finished by several steps. In Step one, we first show the existence of this steady state, then in Step two, we study the stability of this steady state and finally, we demonstrate the existence of threshold $\bar{\lambda}$.

\section{Step 1. Existence}

Suppose that $K_{F} \neq 0$ holds. Setting $\dot{A}_{F}=0, \dot{K}_{F}=0, \dot{\mu}_{1}=0, \dot{\mu}_{2}=0$, we obtain the other variables of this steady state as

$$
\left\{\begin{array}{l}
\widehat{\eta}=0, \\
\widehat{A_{F}}=A_{H F}, \\
\widehat{\mu_{K}}=\frac{A_{H F}}{\delta+r}\left(\frac{w_{H}}{A_{H}}-\frac{w_{F}}{A_{H F}}\right), \\
\widehat{I}=\delta \widehat{K_{F}}=\frac{\widehat{\mu_{K}}-\beta}{2 \gamma}, \\
\widehat{\mu_{A}}=-\frac{1}{r+\lambda \widehat{K_{F}} A_{H F} / 2} \frac{\partial \Pi_{H}^{*}\left(\widehat{K_{F}}, \widehat{A_{F}}\right)}{\partial A_{F}} .
\end{array}\right.
$$

The same arguments as in Dawid et al. (2010), we can show that this fixed point of the canonical system is indeed a steady-state of the optimal policy of firm $\mathrm{H}$.

\section{Step 2. Stability}

To determine stability of this steady state, we consider the Jacobian matrix at the 
steady state which is given by

$$
\begin{aligned}
& J_{I}=\left(\begin{array}{cccc}
-\delta & 0 & \frac{1}{2 \gamma} & 0 \\
\lambda \widehat{A_{F}}\left(A_{H F}-\widehat{A_{F}}\right) & \lambda \widehat{K_{F}}\left(A_{H F}-2 \widehat{A_{F}}\right) & 0 & 0 \\
0 & \lambda \widehat{\mu_{A}}\left(A_{H F}-2 \widehat{A_{F}}\right) & \delta+r & -\lambda \widehat{A_{F}}\left(A_{H F}-\widehat{A_{F}}\right) \\
-\lambda \widehat{\mu_{A}}\left(A_{H F}-2 \widehat{A_{F}}\right) & 2 \lambda \widehat{\mu_{A}} \widehat{K_{F}}-\frac{\partial^{2} \Pi_{H}^{*}\left(\widehat{K_{F}} \widehat{\partial A_{F}}\right)}{0} & 0 & r-\lambda \widehat{K_{F}}\left(A_{H F}-2 \widehat{A_{F}}\right)
\end{array}\right) \\
& =\left(\begin{array}{cccc}
-\delta & 0 & \frac{1}{2 \gamma} & 0 \\
0 & -\lambda \widehat{K_{F}} A_{H F} / 2 & 0 & 0 \\
0 & \lambda \widehat{\mu_{A}} A_{H F} / 2 & \delta+r & 0 \\
\lambda \widehat{\mu_{A}} A_{H F} / 2 & 2 \lambda \widehat{\mu_{A}} \widehat{K_{F}}-\frac{\partial^{2} \Pi_{H}^{*}\left(\widehat{K_{F}}, A_{H F}\right)}{\partial A_{F}^{2}} & 0 & r+\lambda \widehat{K_{F}} A_{H F} / 2
\end{array}\right) .
\end{aligned}
$$

It is easy to show that the eigenvalues of the Jacobian are given by

$$
e_{1}=-\delta<0, \quad e_{2}=\delta+r>0, \quad e_{3}=-\frac{\lambda}{2} A_{H F} \widehat{K_{F}}<0, \quad e_{4}=r+\frac{\lambda}{2} A_{H F} \widehat{K_{F}}>0 .
$$

Since there are two negative and two positive eigenvalues, the fixed-point is a saddle point of the canonical system, and, therefore, the steady state is locally asymptotically stable in its state space.

\section{Step 3. Existence of $\bar{\lambda}$}

We start by considering the necessary conditions that have to be satisfied at a steadystate with $\widehat{K_{F}}=0$. In any such steady state, $\widehat{I}=0$ must hold which implies $\widehat{\mu_{K}}=\beta$. Thus, $\dot{\mu}_{K}=0$ yields

$$
\widehat{\mu_{A}}=\frac{1}{\lambda A_{F}\left(A_{H F}-A_{F}\right)}\left((r+\delta) \beta-A_{H F}\left(\frac{w_{H}}{A_{H}}-\frac{w_{F}}{A_{H F}}\right)-\widehat{\eta}\right) .
$$

Since $\widehat{\eta} \geq 0$, this is equivalent to

$$
\widehat{\mu_{A}} \leq q_{1}\left(A_{F}\right):=-\frac{r+\delta}{\lambda A_{F}\left(A_{H F}-A_{F}\right)}\left(\frac{A_{H F}}{r+\delta}\left(\frac{w_{H}}{A_{H}}-\frac{w_{F}}{A_{H F}}\right)-\beta\right) .
$$


Furthermore, $\dot{\mu}_{2}=0$ yields

$$
\widehat{\mu_{A}}=q_{2}\left(A_{F}\right):=\frac{1}{r} \frac{\partial \pi_{1}^{*}\left(0, A_{F}\right)}{\partial A_{F}} .
$$

This implies that a steady-state with $\widehat{K_{F}}=0$ can only exist for values of $A_{F}$ where $q_{1}\left(A_{F}\right) \geq q_{2}\left(A_{F}\right)$.

It is easy to prove that $q_{1}\left(A_{F}\right)$ is negative and concave in term of $A_{F}$ and checks $\lim _{A_{F} \rightarrow 0} q_{1}\left(A_{F}\right)=\lim _{A_{F} \rightarrow A_{H F}} q_{1}\left(A_{F}\right)=-\infty$, while $q_{2}$ is bounded from below on $\left(A_{F}(0), A_{H F}\right] \subset$ $\left(0, A_{H}\right]$. Therefore, for values of $A_{F}$ sufficiently close to $A_{H F}$, we have $q_{1}\left(A_{F}\right)<q_{2}\left(A_{F}\right)$ and no steady state with $\widehat{K_{F}}=0$ can exist. Thus, $q_{1}\left(A_{F}\right) \geq q_{2}\left(A_{F}\right)$ if and only if at the maximum $A_{F}^{m}=\operatorname{argmax} q_{1}\left(A_{F}\right)$, there is $q_{1}\left(A_{F}^{m}\right) \geq q_{2}\left(A_{F}^{m}\right)$. It is easy to check that $A_{F}^{m}=A_{H F} / 2$.

Define $\bar{\lambda}$ as in the proposition, we finish the proof.

\section{References}

[1] Aitken, B. and A. Harrison (1999), "Do domestic firms benefit from direct foreign investment? Evidence from Venezuela", The American Economic Review, Vol. 89(3), 605-618.

[2] Blomstrom M., S. Globerman and A. Kokko (2001), "The determinants of host country spillovers from foreign direct investment: a review and synthesis of the literature." In Pain, Nigel (Ed.), Inward Investment, Technological Change and Growth: The Impact of Multinational Corporations on the UK Economy. Houndmills, London, UK.

[3] Cheng L. (1984), "International Trade and technology: An brief survey of th erecent literature." Weltwirtschaftliches Archiv, Vol. 120, 165-89. 
[4] Das S. (1987), "Externalities, and technology transfer through multinational corporations: A theoretical analysis." Journal of International Economics, Vol. 22, $171-82$.

[5] Dawid H., A. Greiner and B. Zou (2010), "Optimal foreign investmnet dynamics in the presence of technological spillovers", Journal of Economic Dynamics and Control, Vol. 34, 296-313.

[6] Dawid H. and B. Zou (2014), "Strategies of foreign investmnet dynamics in the presence of technological spillovers", in Dynamic Games in Economics, Edited by J. Haunschmied, W. Veliov and S. Wrzaczek, 2014, Springer, 115-134.

[7] Dockner E., Jorgensen S., Van Long N., and G. Sorger (2000). Differential games in economics and management, Cambridge University Press.

[8] Görg, H. and D. Greenaway (2004) "Much ado about nothing? Do domestic firms really benefit from foreign dircet investment" The World Bank Research Observer, Vol. 19(2), 171-197.

[9] Hymer, S. (1960), The International Operations of National Firms, A Study of Direct Foreign Investment. PhD Thesis, MIT, Cambridge, Mass.

[10] Lim, E. (2001), “Determinants of, and the relation between, foreign direct investment and growth: A summary of the recent literature." IMF Working Paper, No. 01/175, Washington.

[11] Nelson R. and E. Phelps (1966), " Investment in human, technological diffusion and economic growth", American Economic Review, 56, 69-75.

[12] Peri, G. and D. Urban (2006), " Catching-up to foreign technology? Evidence on the 'Beblen-Gerschenkron' effect of frgien investmnets", Regional Science and Urban Economics, Vol. 36, 72-98. 
[13] Petit, M., F. Sanna-Randaccio and B. Tolwinski (2000), "Innovation and foreign direct investment in a dynamic oligopoly." International Game Theory Review, Vol. 2, 1-28.

[14] Saggi, K. (2000), “Trade, foreign direct investment, and international technology transfer: A survey." The World Bank Policy Research Working Paper. No. 2349, Washington.

[15] UNCTAD. Foreign direct investment database online. http://unctadstat.unctad.org/wds/TableViewer/tableView.aspx?ReportId=88

[16] Vedenov, D.and Miranda, M. (2001), "Numerical solution of dynamic oligopoly games with capital investment", Economic Theory, 18, 237261.

[17] Wang J. and M. Blomstrom (1992), "Foreign investment and technology transfer: A simple model" European Economic Review. Vol. 36, 137-55. 